Eur. J. Clin. Chem. Clin. Biochem.

Vol. 32,1994 , pp. $625-628$

(C) 1994 Walter de Gruyter \& Co.

Berlin $\cdot$ New York

\title{
Inulin Measurement in Serum and Urine with an Autoanalyser, Corrected for Glucose Interference
}

\author{
By Eef. G. W. M. Lentjes ${ }^{1}$, K. W. Florijn ${ }^{2}$, P. C. Chang ${ }^{2}$ and W. van Dam ${ }^{1}$ \\ 1 Department of Clinical Chemistry \\ 2 Department of Nephrology \\ University Hospital Leiden, Leiden, The Netherlands
}

(Received Juni 1, 1993/March 21/May 20, 1994)

Summary: A method is described for the semi-automated measurement of inulin concentrations in serum and urine in the presence of glucose. The concentration of glucose is measured simultaneously and is used to correct for almost all "inulin-like" interferences. The inulin standard curve is linear over a wide range $(5-2500 \mathrm{mg} / \mathrm{l})$. Betweenrun precision is $<6 \%$ and recovery from spiked sera is $98 \%$. This method offers the possibility of measuring glomerular filtration rate in patients with varying glucose concentrations (e. g. diabetics).

\section{Introduction}

Inulin is an uncharged fructose polymer with an average relative molecular mass of 5200 . It does not bind to plasma proteins and distributes freely in the extracellular fluid. Inulin is eliminated by filtration through the glomerulus and is not reabsorbed, secreted or metabolised at the tubulus. Thus, renal inulin clearance using a constant infusion is the "gold standard" for measuring glomerular filtration rate, any extrarenal elimination being stable with constant plasma inulin concentrations (1). Most methods for the measurement of inulin in plasma or urine are based on the estimation of fructose. Inulin is hydrolysed to fructose in a protein free filtrate, followed by a colorimetric assay of fructose using $\beta$-indolylacetic acid (2), resorcinol (3) or anthrone (4).

Carbohydrates, especially glucose, interfere with these methods by increasing the absorbance, resulting in an overestimation of the inulin concentration. Unstable plasma glucose concentrations, which may occur in diabetics, result in additional errors, which may be enhanced if glycosuria develops when plasma glucose concentrations are above the renal threshold. Obviously this excludes the use of the inulin clearance test for these patients. To overcome this problem glucose has been eliminated enzymatically prior to the test (5). Alternative methods have been developed using specific enzymatic assays $(6,7)$, or refined techniques such as $\operatorname{HPLC}(8)$, requiring special equipment.

We developed a semi-automated method for inulin determination in serum and urine samples, in which the glucose concentration in measured simultaneously. In this way we are able to correct for almost all the "inulinlike" interference.

\section{Materials and Methods}

Chemicals and solutions

1. Standard inulin solutions: Inulin from Merck (Darmstadt, Germany) was dried in a desiccator for at least 48 hours and dissolved in (hot) water to make a $10000 \mathrm{mg} / \mathrm{l}$ standard solution. From this a $200,400,600,800$ and $1000 \mathrm{mg} / \mathrm{l}$ working standard was prepared.

2. Glucose standard solutions: Glucose was purchased from Merck. The following standard solutions were made: $2.5,5,10$ and 20 $\mathrm{mmol} / \mathrm{h}$.

3. Anthrone solution. Two grams of anthrone (Sigma) was dissolved in $700 \mathrm{~g} / \mathrm{kg}$ sulphuric acid. The solution was stored in the dark and was stable for at least 1 week.

4. Reagents of p.a. quality were obtained from Merck, unless otherwise specified.

5. Boehringer Mannheim $D$-glucose/D-fructose Test Combination (Cat. No. 139106), for the determination of inulin in urine and serum after acid hydrolysis. 


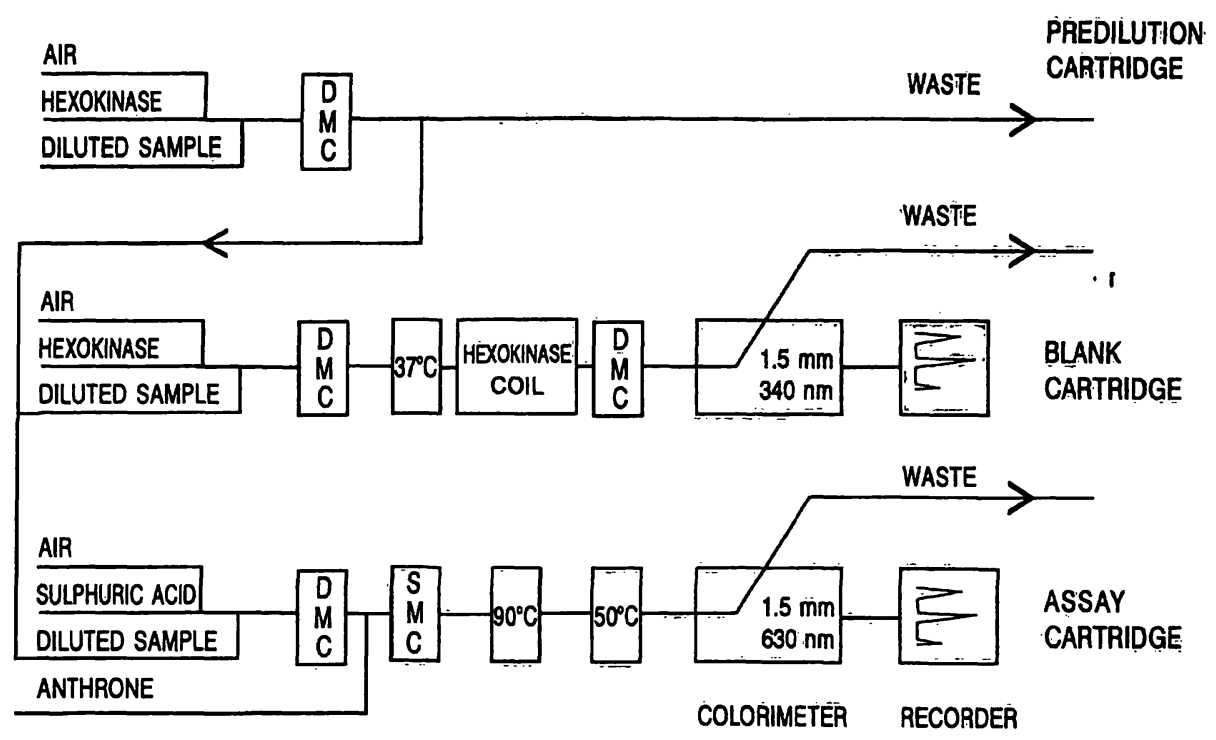

Fig. 1 Flow diagram of the autoanalyser.

For explanation of the components of the flow diagram and the sample flow see text.

Pump tubing: No. $1,4,7$ black/black $(0.32 \mathrm{ml} / \mathrm{min}), 2,5$ grey/grey

\section{General description of the method}

Urine samples are diluted four times with water. Then serum or diluted urine is deproteinized and placed in a sample cup.

After aspiration the inulin in the sample is hydrolysed to fructose in $700 \mathrm{~g} / \mathrm{kg}$ sulphuric acid for $5 \mathrm{~min}$ in a heating bath. Fructose reacts with anthrone to produce a blue-green compound. Its concentration is determined by measuring the absorbance at $630 \mathrm{~nm}$. Glucose is determined in a parallel sample stream. The inulin-like absorbance of the glucose standards measured in the inulin-assayunit is used to construct a glucose correction curve.

$$
\text { : }
$$

\section{Flow procedure in the autoanalyser}

The following units of the Autoanalyser are used: sampler, pumps, single and double mixing coils, heating baths, colorimeters and recorders.

Because inulin cannot be dialysed in this system, a sample $(0.2$ $\mathrm{ml}$ ) is deproteinized manually by the addition of $1.8 \mathrm{ml}$ trichloroacetic acid $(50 \mathrm{~g} / \mathrm{l})$. After mixing and centrifugation $(5 \mathrm{~min}$, $2000 \mathrm{~g}$ ) a portion of the supernatant is placed in a sample cup. Inulin standards are processed the same way as serum samples.

Each sample is diluted 10 -fold with water in the predilution cartridge (fig. 1), then mixed in a double mixing coil, after which the sample stream is split: one part enters the glucose analysing unit ("blank cartridge") using the standard method from Technicon for measurement of glucose with hexokinase. The other part enters the inulin analysing unit ("assay cartridge").

In the assay cartridge the diluted sample is mixed with $700 \mathrm{~g} / \mathrm{kg}$ sulphuric acid in a double mixing coil. Then anthrone solution is added. After complete mixing in a single mixing coil, the solution enters the first heating bath at $90^{\circ} \mathrm{C}$, and after $2.85 \mathrm{~min}$ the second bath at $50^{\circ} \mathrm{C}$ for $2.15 \mathrm{~min}$. By using two baths to lengthen the incubation time, we were able to increase the range of the calibration line. The colorimetric reading is performed in a $1.5 \mathrm{~mm}$ flow cell, with a $630 \mathrm{~mm}$ filter. The acid and anthrone solutions are aspirated from the containers by acidflex tubing.

Sampling time is $90 \mathrm{~s}$. Between two samples, the sampling probe is rinsed and water is aspirated for $90 \mathrm{~s}$. We constructed the inulin and glucose standard curve with five standard solutions of inulin and five standard solutions of glucose respectively.
$(1.00 \mathrm{ml} / \mathrm{min}), 3,6$ orange green $(0.10 \mathrm{ml} / \mathrm{min}), 8,10$ yellow/yellow $(1.20 \mathrm{ml} / \mathrm{min})$ and 9 orange/orange $(0.42 \mathrm{ml} / \mathrm{min})$. Abbreviations: DMC: double mixing coil; SMC: single mixing coil.

\section{Patient material}

Four patients with chronic renal failure and 2 patients with noninsulin-dependent diabetes mellitus received an inulin dose of 75 $\mathrm{mg} / \mathrm{kg}$ lean body mass (9) by intravenous infusion during $5 \mathrm{~min}$. The characteristics of the patients are shown in table 1. A "preinulin" blank sample from every patient was analysed for inulin, corrected for glucose interference, and the remaining "inulin-like" (which is of non-glucose and non-inulin origin) concentration was subtracted from the inulin concentration in the subsequent samples.

In both diabetic patients the interference of an exogeneous dose of glucose on the inulin concentrations was studied by giving a $25 \mathrm{~g}$ glucose solution intravenously at $t=180 \mathrm{~min}$. Serum inulin concentrations corrected for glucose were compared with serum inulin concentrations not corrected for glucose.

\section{Stastistical analysis}

Orthogonal regression analysis was performed according to Deming (10).

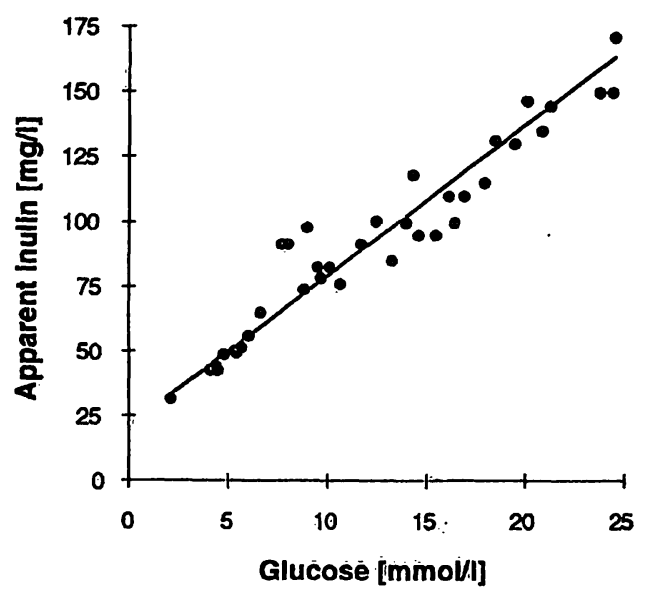

Fig. 2 The interference of glucose in inulin determinations. Apparent inulin concentrations due to glucose interference in the inulin assay, as measured in the sera of 36 patients not receiving inulin. $\left(y=5.9 x+20.8 ; r=0.96 ;{ }^{\prime} s_{y / x}=1.8\right)$. 
Tab. 1 Clinical characteristics and renal function quantities of six patients.

\begin{tabular}{|c|c|c|c|c|c|c|}
\hline & Diagnosis & $\begin{array}{l}\text { Age } \\
\text { [years] }\end{array}$ & Sex & $\begin{array}{l}\text { Body weight } \\
\text { [kg] }\end{array}$ & $\begin{array}{l}\text { Creatinine } \\
\text { clearance } \\
{\left[\mathrm{ml} / \mathrm{min} \cdot 1.73 \mathrm{~m}^{2}\right]}\end{array}$ & $\begin{array}{l}\text { Glomerular } \\
\text { filtration rate } \\
{\left[\mathrm{ml} / \mathrm{min} \cdot 1.73 \mathrm{~m}^{2}\right]}\end{array}$ \\
\hline Patient A & Kidney disease* & 47 & q & 72 & 43 & 28 \\
\hline Patient B & Kidney disease* & 58 & 우 & 77 & 72 & 67 \\
\hline Patient $\mathrm{C}$ & Kidney disease* & 27 & $q$ & 68 & 105 & 99 \\
\hline Patient $\mathrm{D}$ & Kidney disease* & 37 & $\bar{\sigma}$ & 80 & 70 & 54 \\
\hline Patient $\mathrm{E}$ & Diabetes mellitus** & 60 & $\sigma$ & 75 & 25 & 18 \\
\hline Patient $\mathrm{F}$ & Diabetes mellitus** & 68 & $\sigma$ & 79 & 50 & 36 \\
\hline
\end{tabular}

* Autosomal dominant polycystic kidney disease.

** Non-insulin-dependent.

\section{Results}

\section{Methodology}

Within-run precision is better than $0.5 \%$ in the low and the high range of the calibration curve. Between-run precision, measured each day at two levels for 20 days, is $5.8 \%$ at $165 \mathrm{mg} / \mathrm{l}$ and $2.7 \%$ at $400 \mathrm{mg} / \mathrm{l}$. The lowest measurable concentration is $5 \mathrm{mg} / \mathrm{l}$, but sensitivity can be easily increased 10 times by omitting prior dilution or by increasing the sensitivity of the colorimeter.

Recovery experiments performed in eight different sera spiked with inulin show a recovery of $98 \pm 1 \%$. Only minor sample carryover could be detected: inulin concentration increases by $6 \mathrm{mg} / \mathrm{l}(\mathrm{SD} 2 \mathrm{mg} / \mathrm{l}, \mathrm{n}=10)$ in the sample pipetted directly after a $1000 \mathrm{mg} / \mathrm{l}$ sample. The inulin calibration curve is linear over the range from 0 to $2500 \mathrm{mg} / \mathrm{l}$ as checked with 13 standards, the coefficient of correlation being $\mathrm{r}=0.997$.

Glucose interference was investigated, using 36 inulinfree patient serum samples, with different glucose concentrations. The apparent inulin levels in these sera show a linear relationship, as indicated in figure 2. Also endogenous fructose in the patient samples will contribute to the apparent inulin concentration. Using fructose standards in water, the following relation was calculated:

$$
c_{\text {app. inulin }}=175 \times c_{\text {fructose }}-4.8
$$

with inulin in $\mathrm{mg} / \mathrm{l}$ and fructose in $\mathrm{mmol} / \mathrm{l}$. Correlation of this method $(y)$ with the Boehringer Mannheim inulin method $(x)$ gave the following relation:

for serum: $y=0.94 x+29\left(S_{y / x}=38 ; \dot{n}=20\right.$, range of $x: 20-600$ ), and

for urine: $\mathrm{y}=0.91 \mathrm{x}+34\left(\mathrm{~S}_{\mathrm{y} / \mathrm{x}}=195 ; \mathrm{n}=23\right.$, range of $x: 13-2 \overline{7} 00$ ).

\section{Patient studies}

The glomerular filtration rate in patients with different degrees of chronic renal failure, as shown by the creatinine clearance, are shown in table 1 . As is clear from this table, creatinine clearance overestimates true glomerular filtration rate (inulin clearance).

The serum concentration profile of inulin, with and without correlation for glucose in two patients with noninsulin-dependent diabetes mellitus is shown in figure 3. The corrected inulin line shows a decline along the

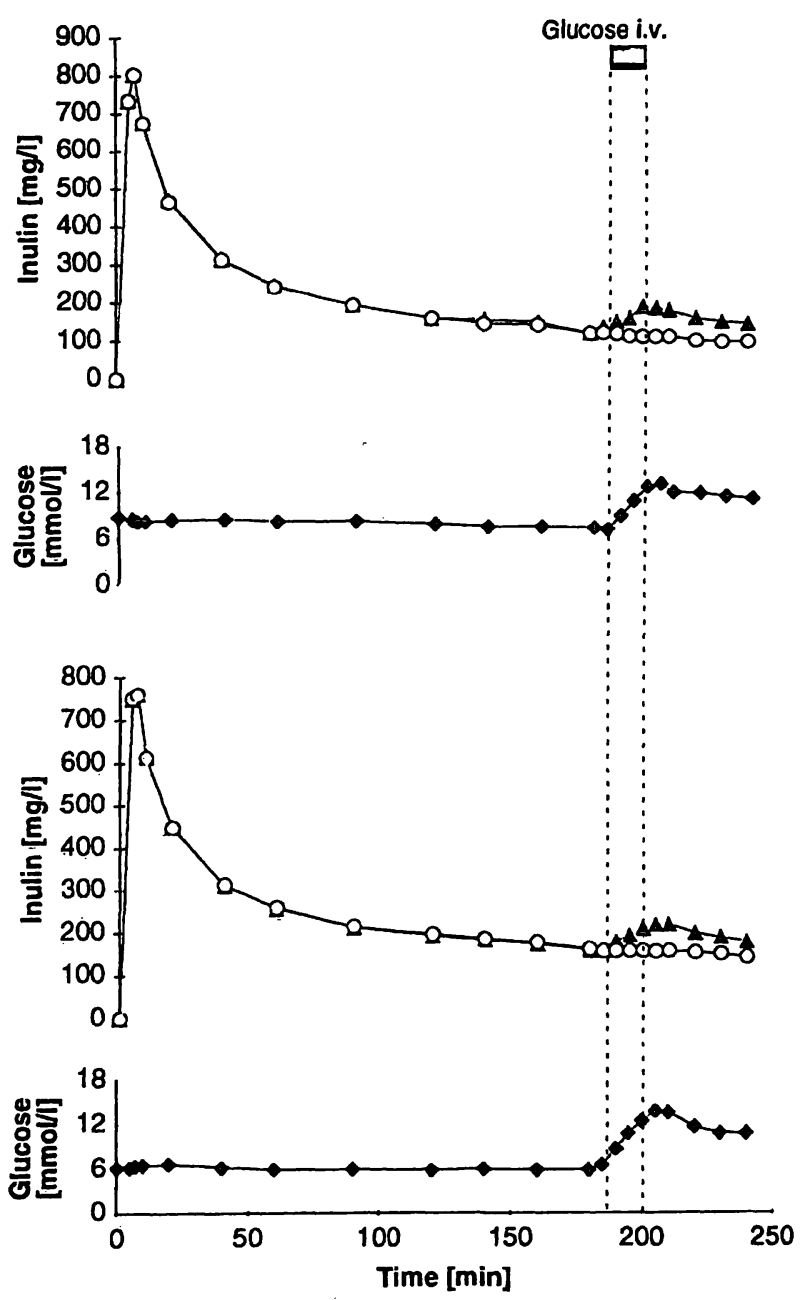

Fig. 3 Serum inulin and glucose profiles in two diabetics. Serum concentration profiles of inulin in time without $(\boldsymbol{\Delta})$ and with (O) correction for glucose interference, together with the serum glucose concentration curve $(\diamond)$ in two patients with non-insulindependent diabetes mellitus (table 1 ). Glucose $(25 \mathrm{~g})$ was infused from $t=180$ to $200 \mathrm{~min}$. The lower profile is from patient $E$, the other is patient $F$. 
extrapolated curve. The uncorrected serum inulin levels, however, show an increase at the terminal elimination phase due to the rise in serum glucose.

\section{Discussion and Conclusion}

\section{Methodology}

The semi-automated method for determining inulin in serum and urine proved to be reliable if corrected for interfering endogenous glucose. The intra- and inter-assay reproducibility is excellent. The assay allows the sequential determination of the broad range of serum and urine inulin concentrations that is encountered when inulin decay curves are used in the determination of glomerular filtration rate (11). No individual dilution steps are required. The necessary deproteinization of serum must be performed manually, but this can be done during spare time, since the samples are stable for at least a week.

From the data in figure 2, it can be calculated that without correction $10 \mathrm{mmol} / \mathrm{l}$ glucose will increase the inulin concentration by $59 \mathrm{mg} / \mathrm{l}$. The intercept of $21 \mathrm{mg} / \mathrm{l}$ (fig. 2 ) is not caused by the non-serum matrix of the glucose standards. Considering the formula describing the relation between the apparent inulin and the fructose concentration, the intercept can be fully explained by the endogenous fructose concentration in the serum: the 21 $\mathrm{mg} / \mathrm{l}$ apparent inulin results from the reaction of anthrone with $0.12 \mathrm{mmol} / \mathrm{l}$ fructose (fructose concentrations in serum range from 0.05 to $3.3 \mathrm{mmol} / \mathrm{l}(12)$ ). The method shows good correlation with the Boehringer Mannheim assay. The latter corrects not only for glucose but also for fructose, and this may be why our method gives somewhat higher results for patient samples. The

\section{References}

1. Brenner, B. M. \& Rector, F. C. (eds.) (1991) The Kidney, WB Saunders Company, fourth edn., pp. 920-937.

2. Heyrovsky, A. (1956) A new method for the determination of inulin in plasma and urine. Clin. Chim. Acta 1, 470-474.

3. Fjeldbo, W. \& Stamey, T. A. (1968) Adapted method for determination of inulin in serum and urine with an autoanalyser. J. Lab. Clin. Med. 72, 353-358.

4. Davidson, W. D. \& Sackner, M. A. (1963) Simplification of the anthrone method for the determination of inulin in clearance studies. J. Lab. Clin. Med. 62, 351-356.

5. Jung, K., Klotzek, S. \& Schulze, B.-D. (1990) Refinements of assays for low concentrations of inulin in serum. Nephron 54, 360-361.

6. Kuehnle, H. F., v. Dahl, K. \& Schmidt, F. H. (1992) Fully enzymatic inulin determination in small volume samples without deproteinization. Nephron 61, 104-107.

7. Summerfield, A. L., Hortin, G. L., Smith, C. H., Wilhite, T. R. \& Landt, M. (1993) Automated enzymatic analysis of inulin. Clin. Chem. 39, 2333-2337.

8. Ruo, T. I., Wang, Z., Dordal, M. S. \& Atkinson, A. J. (1991) Assay of inulin in biological fluids by high performance liquid enzymatic method described by Kuehnle et al. has the advantage not using aggressive chemicals, but this method shows also interference by endogenous glucose and fructose (not mentioned by the authors). When the enzyme, inulinase, becomes commercially available, the enzymatic method will be very'promising.

\section{Patient studies}

The ratio of creatinine to inulin clearance is greater than one in all patients (tab. 1). This is caused by tubular excretion of creatinine in addition to glomerular filtration (1). In calculating true glomerular filtration rate, correction for endogenous glucose is required because the apparent inulin concentration due to glucose interference may contribute up to $50 \%$ of the inulin concentration, especially when levels are low in the terminal elimination phase (fig. 3). In diabetics this may cause erroneously high or low inulin concentrations due to variation in blood glucose concentrations. With the glucose correction, the accuracy of the method in these diabetic patients improves, especially in the lower inulin range. This is in agreement with others (5), who compared a colorimetric asssay with a/specific enzymatic assay and found perfect agreement for low inulin concentrations, only after prior removal of glucose. The resulting clinically important advantage is that by correcting for glucose in each individual sample, the method is suitable for use with diabetics.

In conclusion, this method of measuring inulin concentrations in serum and urine is easy to perform, its accuracy and reproducibility are better than previously reported (2-4), and it can be used for investigations of patients with varying glucose concentrations, like diabetics.

chromatography with pulsed amperometric detection. Clin. Chim. Acta 204, 217-222.

9. Boer, P. (1984) Estimated lean body mass as an index for normalization of body fluid volumes in humans. Am. J. Physiol. 247, F632-F636.

10. Cornbleet, P. J. \& Gochman, N. (1979) Incorrect least-squares regression coefficients in method-comparison analysis. Clin. Chem. 25, 432-438.

11. Jung, K., Henke, W., Schulze, B. D., Sydow, K., Precht, K. \& Klotzek, S. (1992) Practical approach for determining glomerular filtration rate by single-injection inulin clearance. Clin. Chem. 38, 403-407.

12. Tietz, N. W. (ed.) (1986) Textbook for Clinical Chemistry. W. B. Saunders Company, p. 1826.

Eef. G. W. M. Lentjes

University Hospital Leiden

Department of Clinical Chemistry

Building 1, E2-P

Rijnsburgerweg 10

NL-2333 AA Leiden

The Netherlands if 